\title{
Lateral element lengths and nuclear disposition in Lolium
}

\author{
G. JIMÉNEZ \& G. JENKINS* \\ Institute of Biological Sciences, Sir George Stapledon Building, University of Wales, Aberystwyth, Dyfed SY23 3DD, U.K.
}

\begin{abstract}
The 50 per cent difference in nuclear DNA amount between Lolium perenne and L. temulentum translates into a 50 per cent difference in mean total lengths per cell of lateral elements at pachytene, indicating that the same proportion of the genome is incorporated into synaptonemal complexes in these two species. Quantitative comparisons were not able to show that the accommodation of the length differential between homoeologous lateral elements in the diploid $F_{1}$ hybrid is accomplished either by an equal stretching of the shorter chromosomes or a contraction of the longer. $P h$-like genes in one genotype of $L$. perenne appear to induce irregular associations of $\mathrm{A}$ and B chromosomes, whereas in their absence synapsis of A chromosomes is normal and the B chromosome usually segregates to the periphery of the nucleus during meiotic prophase. The differences in chromosome behaviour at this stage have remarkably little effect on bivalent and chiasma frequencies at metaphase $\mathrm{I}$, and on the fertility of the organism.
\end{abstract}

Keywords: B chromosomes, Lolium, synaptonemal complex.

\section{Introduction}

The synaptonemal complex (SC) is a meiosis-specific, tripartite structure of the eukaryote nucleus, which shows a high degree of conservation in terms of ultrastructure and internal dimensions throughout the animal and plant kingdoms. It has been the subject of numerous investigations in a variety of organisms since its discovery (Moses, 1956; Fawcett, 1956), because it not only enables the visualization of the intimate association of chromosomes during synapsis, but also reflects the relative lengths of chromosomes of a complement during meiotic prophase. Indeed, the relative lengths of SCs can be used, with certain caveats (Jones \& de Azkue, 1993) to construct idiograms from which individual pairs of chromosomes may be identified and mapped physically. As SC and chromosome lengths are correlated at the genomic level, the unit length of DNA associated with the SC must be the same throughout the chromosome complement. It is perhaps not surprising, therefore, that a positive relationship has been reported between DNA amount and SC length when different species are compared (Anderson et al., 1985). However, this relationship does not necessarily hold true in all cases. For example, sex-specific (Bojko, 1985; Wallace \& Hulten, 1985; Jones \& Croft, 1989), interplant (de Azkue \& Jones,

${ }^{*}$ Correspondence.
1993) and B chromosome-induced (Jones et al., 1989) SC length variation have been reported recently. Also, an investigation of four vertebrate classes revealed no significant relationship between SC length and genome size (Peterson et al., 1994). Clearly, the proportion of the chromosome length associated with the SC is subject to other controls in these cases.

The present study focuses on comparisons between two closely related species of the genus Lolium, which differ by 50 per cent in nuclear DNA amount (Hutchinson et al., 1979). Previous studies have shown that the difference in homoeologous chromosome length in meiotic nuclei is consistently lower than the expected 50 per cent (Table 1). In other words, it would appear at first glance that the relationship between SC (or lateral element) length and DNA amount breaks down in this material. However, the table shows that all the studies were performed on the $F_{1}$ hybrid, in which there may be distortion of relative lengths owing to differential compaction or elimination of synaptic irregularities. Similar observations have been made in other hybrid organisms. For example, White et al. (1988) and Jenkins et al. (1988) recorded 56 per cent and 37 per cent differences in mean lateral element (LE) length between the chromosome sets of allotriploid and allotetraploid cytotypes of Scilla autumnalis. These compare with estimated differences of 67 per cent in nuclear DNA amount and 47 per cent in somatic metaphase chromosome length. Similarly, 


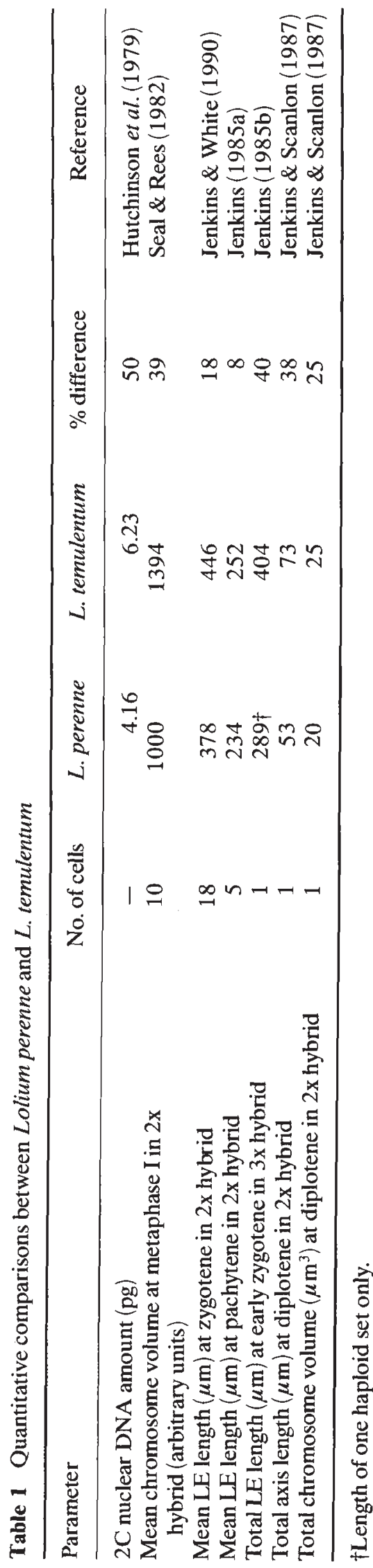

the diploid hybrid between Allium cepa and A. fistulosum has only an 18 per cent difference in length between homoeologous LEs, while the parents differ by 27 per cent in nuclear DNA amount (Albini \& Jones, 1990). The difference in length between chromosome sets may, in other cases, be accentuated relative to the DNA amount. For example, in a hybrid between $L$. multiflorum and Festuca drymeja, the DNA difference is 66 per cent and mean LE length difference between the two asynaptic chromosome sets is 1.00 per cent (Thomas \& Morgan, 1990).

This study presents for the first time comparisons between the lengths of the chromosomes in the parental species, and between the lengths in the parents and in diploid and tetraploid hybrids. It shows the potential of each species to organise LEs, and provides additional information about the mechanics of the accommodation of the length differential in the diploid hybrid. In addition, the selection and comparison of two genotypes of $L$. perenne has revealed a genotypic effect on the nuclear disposition of the $\mathrm{B}$ chromosome and chromosome pairing behaviour of the A complement.

\section{Materials and methods}

\section{Materials}

The two genotypes of $L$. perenne $(2 n=2 \mathrm{x}=14+\mathrm{B})$, Lp10 and Lp19, were isolated by Taylor \& Evans (1977). They are half-sibs and contain a single identical B chromosome. Lp19 contains $P h$-like genes which reduce chiasmate association in the diploid hybrid with L. temulentum and promote homologous bivalent association in the amphidiploid. Both genotypes have been maintained by vegetative propagation in $17.5 \mathrm{~cm}$ pots in a glasshouse.

The two genotypes of L. temulentum $(2 n=2 \mathrm{x}=14)$, Ba3081 and Ba6902, were originally obtained by Taylor \& Evans (1977) from the Welsh Plant Breeding Station, Aberystwyth. Ba3081 was collected locally and Ba6902 from France. They are both naturally inbreeding and annual and have been maintained by selfing since their acquisition. Seed was sown in February into John Innes no. 2 compost in 24-hole multipots. Seedlings were transferred to $12.5 \mathrm{~cm}$ pots and grown to maturity in an unheated greenhouse.

\section{Methods}

The preparation, visualization and analysis of wholemount surface-spread SC complements is described in Chatterjee \& Jenkins (1993). Chromosome pairing behaviour at metaphase I was analysed by conventional 
light microscopy of aceto-carmine squash preparations of anthers fixed in Carnoys. Pollen fertility in $L$. perenne was assessed according to the method of Alexander (1969). Viable and aborted pollen grains were scored from random sectors of slides prepared from the anthers of different plants of the two genotypes.

\section{Results and discussion}

\section{Lateral element lengths}

Table 2 shows the mean LE lengths per cell at pachytene in the two genotypes of $L$. perenne and of $L$. temulentum. Students' $t$-tests show that there is no significant difference between the means of the two genotypes of $L$. temulentum $\left(t_{18}=1.822, P>0.05\right)$ nor of the two genotypes of $L$. perenne $\left(t_{47}=1.354\right.$, $P>0.05)$. The former comparison uses a mean LE length based upon only four nuclei of Ba3081. An estimate derived from such a small sample of cells could be unreliable if there is considerable stage-dependent variation in LE length during pachytene in this genotype. In comparing the mean LE lengths of the two species, Lp10 was selected in preference to $\mathrm{Lp} 19$, as only in the former genotype is it possible to identify positively the B chromosome at this stage and to exclude its length from the mean. Ba6902 was chosen as the other representative as many more nuclei were available for comparison. The mean LE lengths of $\mathrm{Lp} 10$ and $\mathrm{Ba} 6902$ are $672 \mu \mathrm{m}$ (excluding the length of the B chromosome) and $1008 \mu \mathrm{m}$, respectively. This represents a difference of approximately 50 per cent, which corresponds with the DNA difference between the two species. Clearly, there are proportionally longer SCs in L. temulentum, reflecting the association of the same unit length of DNA with the SC in both species.

The same correspondence has been found in other organisms. Volter (1992) recorded comparable differ- ences of 64 per cent in DNA amount and 63 per cent in LE length between Vicia faba and $V$. hybrida. Similarly, comparisons between Schistocerca gregaria and Locusta migratoria showed that the same proportion of DNA is associated with the SC in both species (Jones et al., 1983). However, the relationship does not necessarily hold for all species. For example, the difference between mean LE lengths of two diploid races of Scilla autumnalis is 26 per cent, much lower than the DNA difference of 67 per cent (White et al., 1988). Allium cepa and A. fistulosum differ by 27 per cent in DNA amount but have virtually the same mean lengths of SCs (Albini \& Jones, 1988). In drawing conclusions from these deviations from expectation, it must be borne in mind that some comparisons were based on very small numbers of nuclei. In these cases, stagedependent variation in SC length could greatly distort the means used in the analyses.

Table 1 and Fig. 1 show that the 50 per cent difference in length between $L$. perenne and $L$. temulentum LEs is greatly reduced during meiotic prophase in the diploid $F_{1}$ hybrid. This has been attributed to the accommodation of the length differential into the $\mathrm{SC}$ as synapsis progresses because the difference during zygotene of 18 per cent (Jenkins \& White, 1990) is further reduced to only 8 per cent as synapsis is completed (Jenkins, 1985a). Furthermore, these figures are considerably smaller than those recorded in situations where homoeologues are not associated, namely at early zygotene in a triploid hybrid (Jenkins, 1985b) and at diplotene in a diploid hybrid (Jenkins \& Scanlon, 1987). The actual mechanics of the accommodation process in the hybrid is not understood. Clearly, it must involve either a stretching of the shorter LEs belonging to $L$. perenne, a contraction of the longer LEs of $L$. temulentum, or proportions of both. To determine the relative contributions of stretching and contraction of LEs to the accommodation process would require accurate comparisons of absolute lengths of parental and hybrid LEs at the same stage of meiotic prophase

Table 2 Mean LE lengths and mean frequencies of A chromosome bivalents (II), univalents (I) and chiasmata at pachytene and metaphase I of meiosis in the two genotypes of Lolium temulentum and L. perenne

\begin{tabular}{|c|c|c|c|c|c|c|c|c|}
\hline \multirow[b]{2}{*}{ Genotype } & \multicolumn{4}{|c|}{ Pachytene } & \multicolumn{4}{|c|}{ Metaphase I } \\
\hline & No. of cells & II & I & $\mathrm{LE}$ length $(\mu \mathrm{m})$ & No. of cells & II & I & Chiasmata \\
\hline Ba6902 & 16 & 7.00 & 0.00 & 1008 & 90 & 6.96 & 0.09 & 13.36 \\
\hline Ba3081 & 4 & 7.00 & 0.00 & 1149 & 60 & 6.98 & 0.03 & 13.56 \\
\hline Lp10 & 23 & See text & See text & 696 & 40 & 6.98 & 0.05 & 12.62 \\
\hline Lp19 & 26 & See text & See text & 624 & 40 & 7.00 & 0.00 & 12.62 \\
\hline
\end{tabular}

The complexity of synapsis at pachytene of some cells of the L. perenne genotypes prohibited estimation of mean frequencies of pairing configurations per cell. 


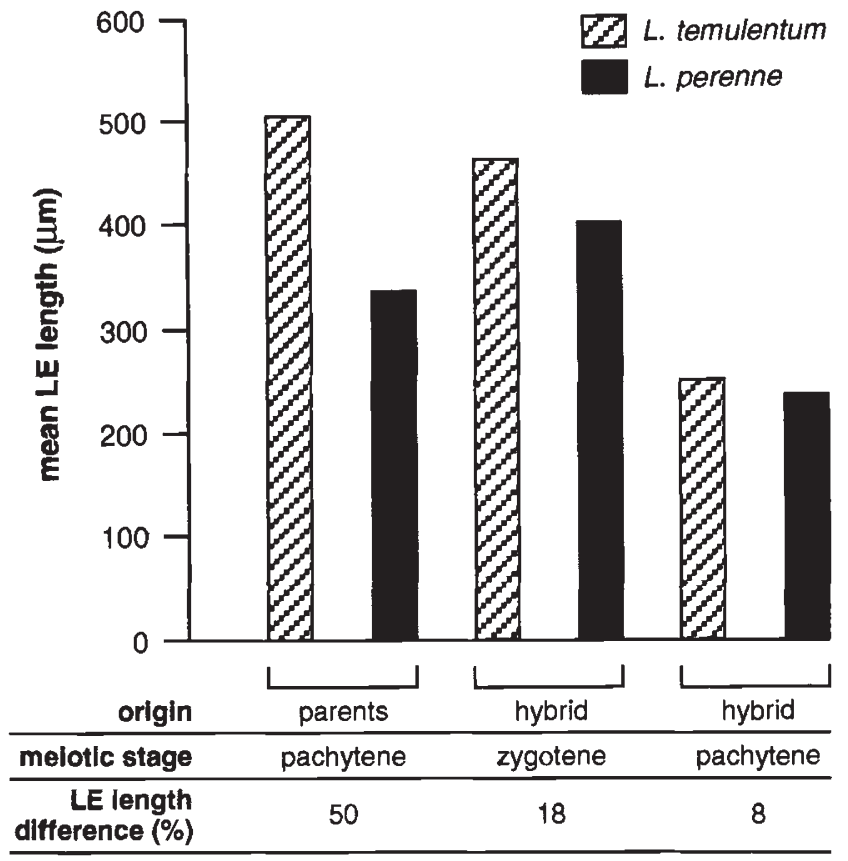

Fig. 1 Diagrammatic representation of the mean total lengths of lateral elements of the haploid sets of chromosomes in the parental species, Lolium perenne and L. temulentum, and the diploid hybrid. The mean total lengths at zygotene in the hybrid are derived from 35 cells, whereas the mean difference is based on 18 cells only.

to minimize stage-dependent variation in chromosome length. Although two populations of parental and hybrid cells at pachytene were available for comparison, Fig. 1 illustrates that the LE lengths of the latter are considerably shorter and are probably derived from cells that had progressed further through pachytene.

Subject to the constraints given above, a crude comparison is possible between the mean LE length in tetraploid hybrids and their parental species. The mean LE length of 54 tetraploid hybrid nuclei of mixed parental origin is $1309 \mu \mathrm{m}$. Data from different amphidiploid genotypes were pooled to increase the sample size, and to include cells in which B chromosomes could not be identified. This compares with a predicted mean of $1738 \mu \mathrm{m}$, based on the sum of the two mean LE lengths of the parental species (Table 2). The actual mean derived from the tetraploids is about 25 per cent less than expected. This deviation could be attributable to differential contraction of the two chromosome sets in the hybrid or to stage-dependent variation in chromosome length. A comparable analysis was performed in Scilla autumnalis, in which the mean length of LEs in the tetraploid differed insignificantly from expectations (Jenkins et al., 1988).

\section{Chromosome behaviour and nuclear disposition}

Table 2 shows the mean frequencies of pairing configurations and chiasmata at pachytene and metaphase I in the four diploid parental genotypes. Twelve of the 16 nuclei of Ba6902 each contained seven completely synapsed bivalents. The remaining four nuclei of this genotype had seven bivalents also, but with small regions of asynapsis in the vicinity of the nucleolar organizing regions or associated with interlocks. One of the four nuclei of $\mathrm{Ba} 3081$ had seven fully synapsed bivalents, whereas the SCs of the other three were interrupted in the vicinity of the nucleolar organizing regions. Metaphase $\mathrm{I}$ in both genotypes of $L$. temulentum is highly regular, with a preponderance of ring bivalents and very low univalent frequencies. Analysis of variance based on three plants of Ba6902 and two of Ba3081 indicates that the mean chiasma frequencies of the two genotypes are not significantly different $\left(F_{1,4}=3.6 ; P>0.05\right)$. In summary, meiotic chromosome behaviour in the two genotypes appears to be completely normal and regular.

A total of 23 nuclei of Lp10 were analysed, of which 21 contained seven regular SCs and a B chromosome univalent. In the absence of a pairing partner, the axial element of the B chromosome typically forms hairpin structures and small foldback loops (Fig. 2). These synaptic configurations are essentially the same as those observed in a reconstructed B chromosome of $L$. perenne (Jenkins, 1985a), and in surface-spread univalent B chromosomes of Vulpus fulvus (Switonski et al., 1987) and Secale cereale (Santos et al., 1993; Jiménez et al., 1994). The intrachromosomal SCs formed in these cases are nonhomologous and contrast with the homologous interarm SCs formed within supernumerary isochromosomes of species such as Euthystira brachyptera and Myrmeleotettix maculatus (Fletcher \& Hewitt, 1988), Apodemus peninsulae (Kolomiets et al., 1988), Crepis capillaris (Jones et al., 1989) and Secale cereale (Santos et al., 1995).

In 18 of the 21 nuclei of Lp10 the B chromosome occupied a peripheral location in the nucleus (Fig. 2), as has been observed in rye (Santos et al., 1993, 1995; Jiménez et al., 1994) and in Crepis capillaris (Jones et al., 1989). The B chromosome of the three other nuclei was more integrated into the nucleus, but did not associate in any way with the A chromosome complement (Fig. 3). The remaining two of the 23 nuclei contained B chromosomes which were associated with the A chromosomes (Fig. 4). The association of supernumerary chromosomes with the normal complement is not a common occurrence, having been documented only twice to date in Zea mays (Gillies, 1983) and in Secale cereale (Díez et al., 1993). Furthermore, the 
Fig. 2 Electron micrographic montage of the SC complement of Lolium perenne genotype $\mathrm{Lp} 10$. Note that the B chromosome (arrow) is folded back on itself and occupies a peripheral location in the nucleus. Bar represents 10 $\mu \mathrm{m}$.

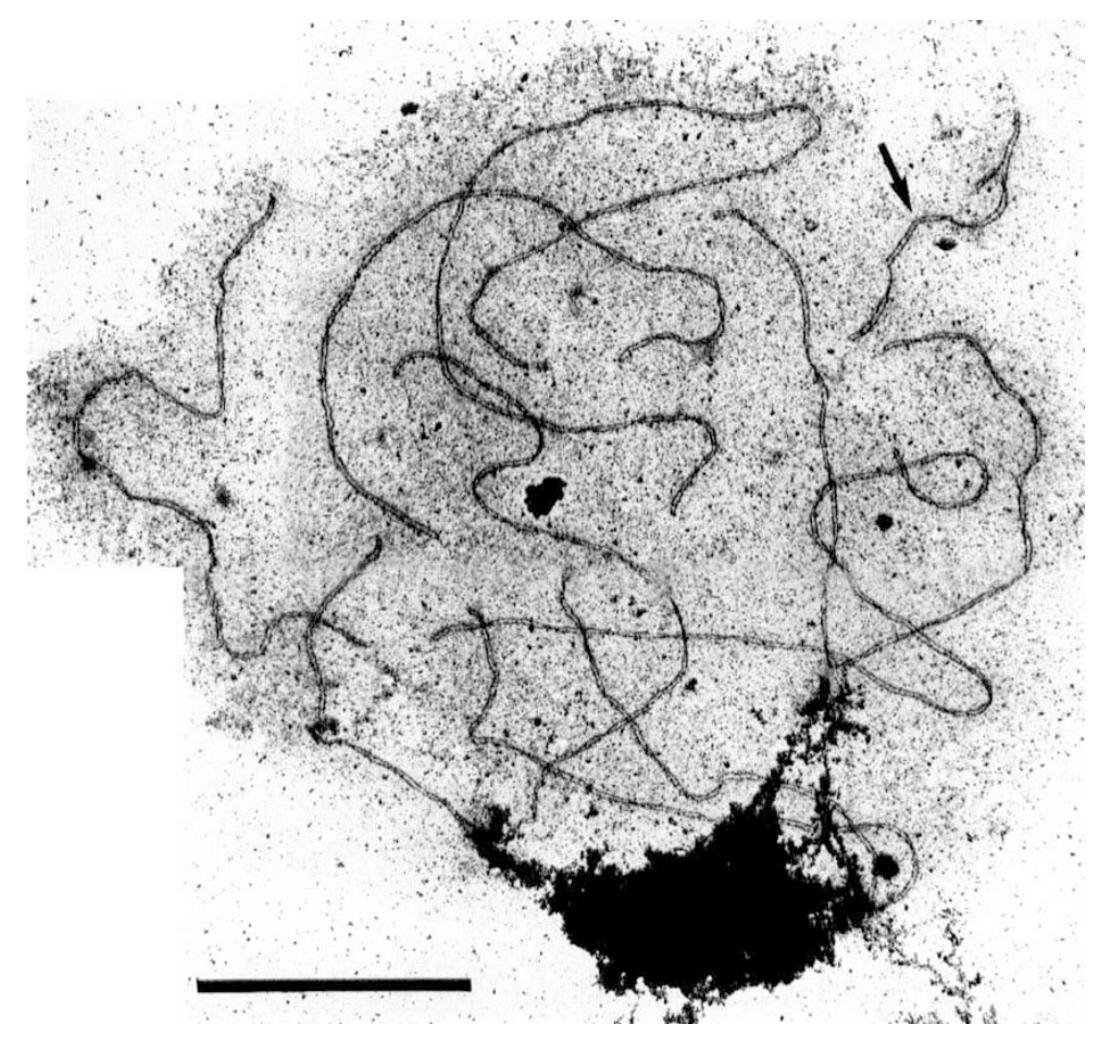

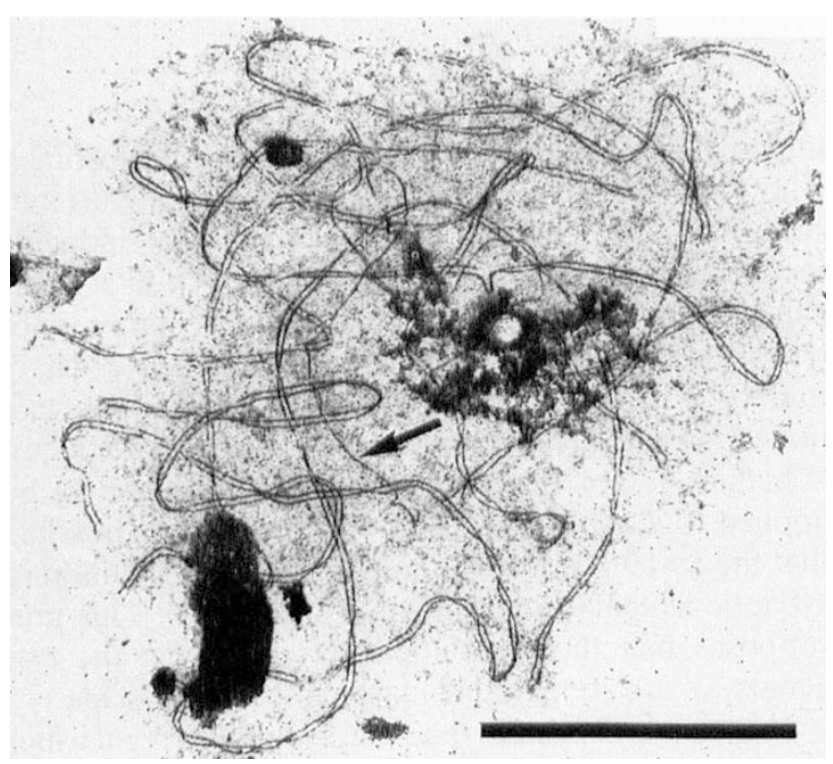

Fig. 3 Electron micrograph of Lolium perenne genotype Lp10 showing a centrally located B chromosome lateral element (arrow) which does not synapse or interfere with the A chromosome SCs. Bar represents $10 \mu \mathrm{m}$.

extent of synapsis in both cases is somewhat limited and confined either to rearranged chromosomes or to regions of impaired synapsis because of interlocking. The synaptic behaviour of the B chromosome in Lp10 of this report and in a total of 16 other reports to date covering nine different organisms would infer that this chromosome has retained little homology with the A chromosomes from which it is presumably derived. Alternatively, in Lp10 at least the B chromosome retains some degree of homology, but is prevented from synapsis with the A chromosomes by its spacial isolation.

A total of 26 nuclei of Lp19 were analysed. In stark contrast to Lp10, no B chromosomes of this genotype occupied a peripheral domain of the nucleus. Ten of the 26 nuclei contained seven regular SCs and a B chromosome univalent which did not associate with the A chromosomes and which formed intrachromosomal synaptic configurations similar to those of Lp10. In each of the remaining 16 nuclei, it was impossible to trace seven SCs and the B univalent, because from one to six bivalents and the $\mathrm{B}$ chromosome were involved in complex and irregular associations (Fig. 4). Because of the tangled nature of these configurations, it was not possible in all cases to ascertain whether the chromosomes were associated by interlocking, simple hooking, or exchanging of pairing partners. Nevertheless, it is obvious that the synaptic behaviour of the chromosomes is different in this genotype compared with Lp10. Indeed, a two-by-two $\chi^{2}$ heterogeneity test indicates that there is a highly significant difference $\left(\chi^{2}=14.66 ; P<0.001\right)$ between Lp10 and Lp19 in 


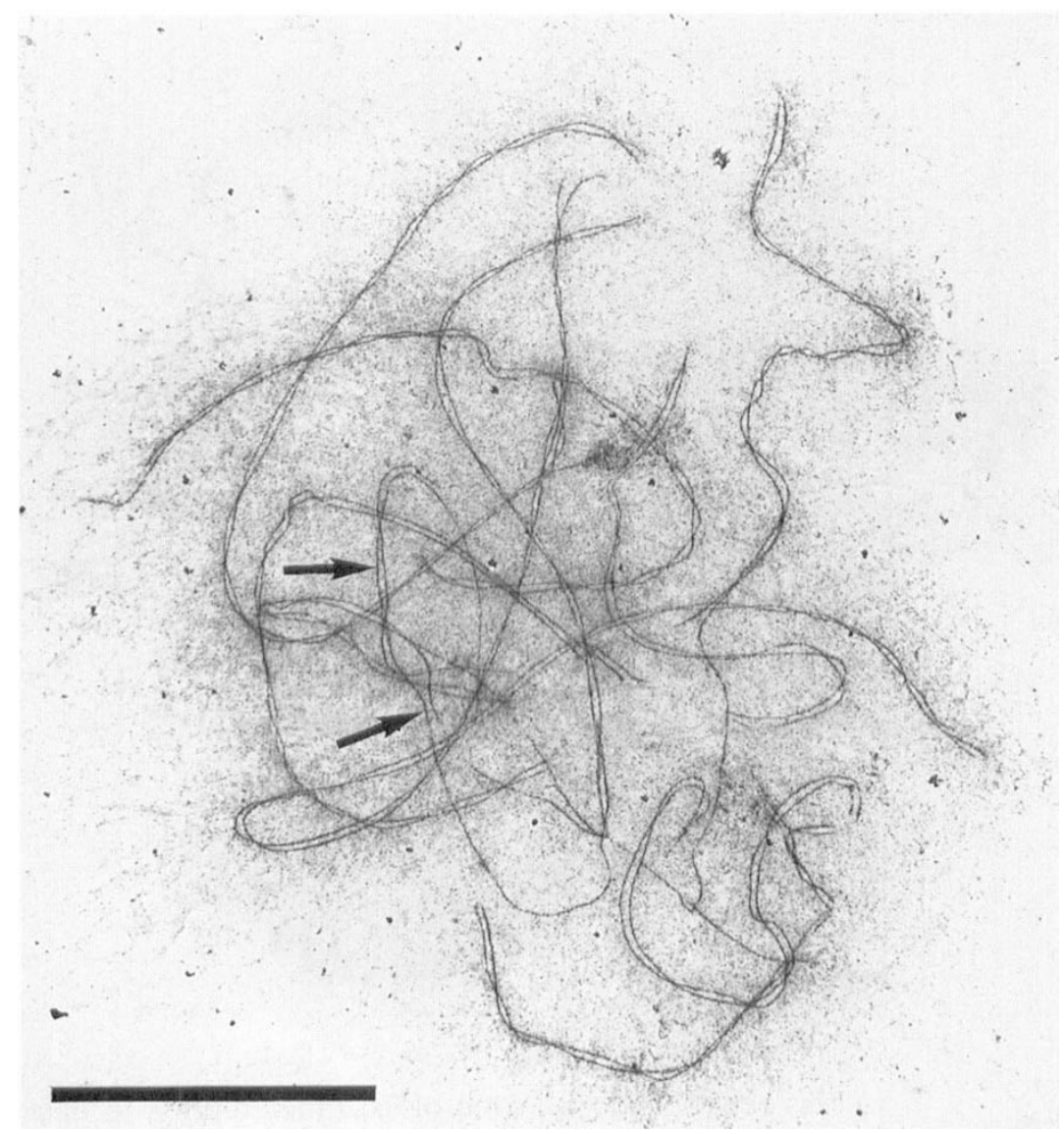

Fig. 4 Electron micrographic montage of Lolium perenne genotype Lp19 showing a B chromosome lateral element synapsing with two A chromosome segments (arrows). Bar represents $10 \mu \mathrm{m}$. terms of the numbers of nuclei with seven bivalents plus the $\mathrm{B}$ chromosome, and with one to six traceable bivalents. As the $\mathrm{B}$ chromosome is identical in the two genotypes, it can be inferred that the A chromosomes are responsible for the difference in behaviour. These observations contrast with those of a study of rye (Díez et al., 1993), in which it was shown that dosage of $\mathrm{B}$ chromosomes influenced the synaptic behaviour of the A chromosome set.

The genetic and cytological basis of the difference in synaptic behaviour between the two genotypes is not known. Attributing the effect to the presence of $P h$-like genes in Lp19 would at first sight appear counterintuitive because these genes are known to enhance the stringency of synapsis in hybrids with $L$. temulentum (Jenkins, 1988). However, if the genes simply promote homologous synapsis at the expense of nonhomologous synapsis, it may be argued that they could actually enhance synapsis between homologous segments which are shared by heterologous chromosomes. This mode of action fails to explain why these segments fail to cross over and form chiasmata. An alternative explanation is that the Lp19 genotype fails to segregate the $\mathrm{B}$ chromosome to the periphery of the nucleus, and as a consequence permits the $\mathrm{B}$ chromosomes to impair the integrity of synapsis of the A chromosomes. The corollary is that Lp10 segregates the B chromosomes and effectively prevents them from inducing meiotic disturbances. The notion that $P h$-like genes can alter the nuclear disposition of chromosomes is not new. Feldman (1966) attributed the diploid-like behaviour of Triticum aestivum to the preferential association of homologues under the influence of the $P h$ locus. Whether or not this explanation can legitimately be applied to Lolium is not known. Finally, it is possible that the Lp19 genotype simply delays the resolution of synaptic irregularities compared with Lp10. This presupposes that the populations of cells from the two genotypes are comparable in terms of meiotic stage.

It may be expected that the synaptic irregularities observed in Lp19 during meiotic prophase would have a detrimental effect on the frequencies of bivalents and chiasmata at metaphase I. However, examination of the data in Table 2 shows that this is not the case. The mean bivalent frequency per cell in the two genotypes is virtually identical and there is no difference in mean chiasma frequencies per cell. To ensure that the samples of cells taken at metaphase I from the two genotypes were representative and not inadvertently selected on the basis of their regularity, a check on 
pollen fertility was made. A two-by-two $\chi^{2}$ heterogeneity test indicated that the proportions of fertile and infertile pollen grains in four plants of the two genotypes were not significantly different $\left(\chi^{2}=0.097\right.$; $P>0.05)$. The conclusion is, therefore, that the irregularities at meiotic prophase do not influence the frequencies of pairing configurations and chiasmata at metaphase I and do not affect pollen fertility. It follows that the irregularities must occur in regions of the chromosomes that do not engage in recombination. Alternatively, the synaptic irregularities are resolved by dissolution and reassembly of SCs before crossing-over takes place. Such a mechanism would bear a remarkable similarity to that observed in the diploid hybrid between $L$. perenne and $L$. temulentum (Jenkins \& White, 1990).

\section{Acknowledgements}

We thank the EM Unit and Julia Bowler for technical assistance, and the Science and Engineering Research Council (grant no. GR/F 73267) and the Royal Society for financial support to G. Jenkins.

\section{References}

ALBINI, S. M. AND JONES, G. H. 1988. Synaptonemal complex spreading in Allium cepa and Allium fistulosum. II. Pachytene observations: the SC karyotype and the correspondence of late recombination nodules and chiasmata. Genome, 30, 399-410.

ALbINI, S. M. AND JONES, G. H. 1990. Synaptonemal complex spreading in Allium cepa and Allium fistulosum. III. The $\mathrm{F}_{1}$ hybrid. Genome, 33, 854-866.

ALEXANDER, M. P. 1969. Differential staining of aborted and non-aborted pollen. Stain Technol., 44, 117-122.

ANDERSON, L. K., STACK, S. M., FOX, M. H. AND CHUANSHAN, Z. 1985. The relationship between genome size and synaptonemal complex length in higher plants. Exp. Cell Res., 156, 367-378.

војко, м. 1985. Human meiosis. IX. Crossing over and chiasma formation in oocytes. Carlsberg Res. Comm., 50, 43-72.

CHATTERJEE, R. AND JENkins, G. 1993. Meiotic chromosome interactions in inbred autotetraploid rye (Secale cereale). Genome, 36, 131-138.

DE AZKUE, D. AND JONES, G. H. 1993. Inter- and intra-plant SC length variation in Crepis capillaris. Heredity, 71, 363-368.

DÍEZ, M., JIMÉNEZ, M. M. AND SANTOS, J. L. 1993. Synaptic patterns of rye $\mathrm{B}$ chromosomes. II. The effect of the standard $\mathrm{B}$ chromosomes on the pairing of the A set. Theor. Appl. Genet., 87, 17-21.

FAWCETT, D. W. 1956. The fine structure of chromosomes in the meiotic prophase of vertebrate spermatocytes. $J$. Biophys. Biochem. Cytol., 2, 403-406.
FELDMAN, M. 1966. The effect of chromosomes 5B, 5D and $5 \mathrm{~A}$ on chromosomal pairing in Triticum aestivum. Proc. Natl. Acad. Sci. U.S.A., 55, 1447-1453.

FLETCHER, H. L. AND HEWITT, G. M. 1988. Synaptonemal complexes of univalent B chromosomes in the grasshoppers Euthystira brachyptera and Myrmeleotettix maculatus. Heredity, 60, 383-386.

GILLIES, C. B. 1983. Ultrastructural studies of the association of homologous and non-homologous parts of chromosomes in the mid-prophase of meiosis in Zea mays. Maydica, 28, 265-287.

HUTCHINSON, J., REES, H. AND SEAL, A. G. 1979. An assay of the activity of supplementary DNA in Lolium. Heredity, 43, 411-421.

JENKINS, G. 1985a. Synaptonemal complex formation in hybrids of Lolium temulentum $\times$ Lolium perenne (L.). I. High chiasma frequency diploid. Chromosoma, 92, 81-88.

JENKINS, G. 1985b. Synaptonemal complex fomation in hybrids of Lolium temulentum $\times$ Lolium perenne (L.). II. Triploid. Chromosoma, 92, 387-390.

JENKINS, G. 1988. Chromosome pairing in Lolium hybrids. In: Brandham, P. E. (ed.) Kew Chromosome Conference III, pp. 261-267. HMSO, London.

JENKINS, G. AND SCANLON, M. J. 1987. Chromosome pairing in a Lolium temulentum $\times$ Lolium perenne diploid hybrid with a low chiasma frequency. Theor. Appl. Genet., 73, 516-522.

JENKINS, G. AND WHITE, J. 1990. Elimination of synaptonemal complex irregularities in a Lolium hybrid. Heredity, 64, 45-53.

JENKINS, G., WHITE, J. AND PARKER, J. S. 1988. Elimination of multivalents during meiotic prophase in Scilla autumnalis. II. Tetraploid. Genome, 30, 940-946.

Jiménez, G. 1994. The Genetic Control of Chromosome Synapsis and Recombination. Ph. D. Thesis, University of Wales.

JIMÉNEZ M., DÍEZ, M. AND SANTOS, J. L. 1994. Synaptic patterns of rye $\mathrm{B}$ chromosomes. III. The deficient B. Chrom. Res., 2 , 93-98.

JONES, G. H. AND CROFT, J. A. 1989. Chromosome pairing and chiasma formation in spermatocytes and oocytes of Dendrocoelum lacteum (Turbellaria, Tricladida); a cytogenetical and ultrastructural study. Heredity, 63, 97-106.

JONES, G. H., CROFT, J. A. AND WALlaCE, B. M. N. 1983. Synaptonemal complexes in surface-spread preparations of orthopteran spermatocytes. In: Brandham, P. E. and Bennett, M. D. (eds) Kew Chromosome Conference II, pp 123-130. Allen and Unwin, London.

JONES, G. H. AND DE AZKUE, D. 1993. Synaptonemal complex karyotyping: an appraisal based on a study of Crepis capillaris. Chrom. Res., 1, 197-203.

JONES, G. H., WHITEHORN, J. A. F. AND ALBINI S. M. 1989. Ultrastructure of meiotic pairing in B chromosomes of Crepis capillaris. I. One-B and two-B pollen mother cells. Genome, 32, 611-621.

KOLOMIETS, O. L., BORBIEV, T. E., SAFRONOVA, L. D., BORISOV, Y. M. AND BOGDANOV, Y. F. 1988. Synaptonemal complex analysis of $\mathrm{B}$-chromosome behaviour in meiotic prophase $\mathrm{I}$ in the 
East-Asiatic mouse Apodemus peninsulae (Muridae, Rodentia). Cytogenet. Cell Genet., 48, 183-187.

MOSES, M. J. 1956. Chromosomal structures in crayfish spermatocytes. J. Biophys. Biochem. Cytol., 2, 215-217.

PETERSON, D. G., STACK, S. M., HEALY, J. L., DONOHOE, B. S. AND ANDERSON, L. K. 1994. The relationship between synaptonemal complex length and genome size in four vertebrate classes (Osteicthyes, Reptilia, Aves, Mammalia). Chrom. Res., 2, 153-162.

SANTOS, J. L., JIMÉNEZ, M. M. AND DIEZ, M. 1993. Synaptic patterns of rye B chromosomes. I. The standard type. Chrom. Res., $1,145-152$.

SANTOS, J. L., JIMENEZ, M. M. AND DIEZ, M. 1995. Synaptic patterns of rye B chromosomes. IV. The B isochromosomes. Heredity, 74, 100-107.

SEAL, A. G. AND REES, H. 1982. The distribution of quantitative DNA changes associated with the evolution of diploid Festuceae. Heredity, 49, 179-190.
SWITONSKI, M., GUSTAVSSON, I., HOJER, K. AND PLOEN, L. 1987. Synaptonemal complex analysis of the B-chromosomes in spermatocytes of the silver fox (Vulpes fulvus Desm.). Cytogenet. Cell Genet., 45, 84-92.

TAYLOR, I. B. AND EVANS, G. M. 1977. The genotypic control of homoeologous chromosome association in Lolium temulentum $\times$ Lolium perenne interspecific hybrids. Chromosoma, 62, 57-67.

THOMAS, H. M. AND MORGAN w. G. 1990. Analysis of synaptonemal complexes and chromosome pairing at metaphase I in the diploid intergeneric hybrid Lolium multiflorum $\times$ Festuca drymeja. Genome, 33, 465-471.

volter, L. J. 1992. Recombination and Genome Size. Ph.D Thesis, University of Wales.

WALLACE, B. M. N. AND HULTEN, M. A. 1985. Meiotic chromosome pairing in the normal human female. Ann. Hum. Genet., 49, 215-226.

WHITE, J., JENKINS, G. AND PARKER, J. S. 1988. Elimination of multivalents during meiotic prophase in Scilla autumnalis. I. Diploid and triploid. Genome, 30, 930-939. 